\title{
Scenario Based Requirements Generation Tools for Organisational Design
}

\author{
Ken Eason and Susan Harker \\ Department of Human Sciences \\ Loughborough University \\ Leics. LE11 3TU, UK. \\ E-mail:k.d.eason@lboro.ac.uk s.d.harker@lboro.ac.uk
}

\begin{abstract}
The tutorial provides participants with an understanding of the techniques available to assist with the development of options for organisational and technological change. The options provide a basis for evaluation and enable the specification of requirements for computer based systems. Experience of using of one of the techniques is applied to a case study based on the introduction of tele-medicine.
\end{abstract}

KEY WORDS Organisation, Users, Technological Change, Requirements

\section{BACKGROUND}

Modern information teclnology has the potential to transform the world of work. User organisations are faced with opportunities to exploit the capability of the technology to support virtual businesses, teleworking, electronic commerce, inter-organisational co-operation and many other things. Such developments offer the opportunity to become more competitive, to build new relationships with their suppliers and customers, to have staff work at home or in 'virtual settings', for example. Organisations contemplating such changes have little current experience of the relevant technology and therefore find it difficult to anticipate the effects it would have on their business or their staff. They may not appreciate that there are many different ways in which the technology may be applied nor that it may transform their ways of working in unanticipated ways. As a result, when they invest in new systems they often do so without a clear set of requirements or understanding of the issues that will be raised. These problems are manifest in the high rate of failure which occurs when organisational change accompanies technical innovation (Kearney 1994, LAS 1993).

\section{THE OBJECTIVE}

The objective of this tutorial is to provide participants with the opportunity to explore techniques which can be used to help people within organisations clarify their requirements when they are contemplating major change. These techniques seek to develop models of the future based on the user organisation and the technology. They provide the means for members of an organisation to evaluate the visions of the future embodied in the models in order that they can determine their requirements in relation to both the nature of the organisation and the form of information technology which is needed. One of these techniques is presented in depth in order to provide delegates with the opportunity to gain experience of how it works by applying it to a particular case study.

\section{CONTENT}

The techniques covered bring together a number of strands of work on requirements capture. They extend the concept of early prototyping of interfaces to the creation of prototypes with a broader socio-technical 
vision which include the future user roles and tasks as well as the technology. Another contribution comes from systems analysis techniques used to express organisational as well as technical requirements, including enterprise modelling (Martin and Dobson 1991), soft-systems analysis (Checkland 1981) and socio-technical systems analysis (Emery and Trist 1969). The way in which users need to be engaged with these techniques owes much to participative design techniques such as ETHICS (Mumford 1983) and to the forms of user participation practised in Search Conferences (Weisbord 1990)

The tutorial classifies the different approaches and assesses their strengths and weaknesses. The aim is to give attendees the opportunity to examine the issues associated with working with this kind of technique. The method presented in detail is ORDIT (Eason and Olphert 1996) (Organisational Requirements Definition for Information Technology Systems). This technique embodies the following features

(i) a method of modelling the socio-technical system which is based upon work roles, responsibilities and role relations which provides an integrating set of concepts linking the business process, the organisation and the technical system,

(ii) techniques for generating alternative models of future systems based upon early statements of user requirements,

(iii) ways of representing the alternative models in order that user participants can experience the essential elements of the future way of working and

(iv) evaluation techniques which enable users to assess a broad range of implications and as a result develop an informed set of requirements for the future system to be implemented.

The ORDIT approach is worked on using a case study in which a medical authority is planning to introduce tele-medicine linking local doctors (General Practitioners) and consultants in hospitals as a means of reducing the need for patients to travel for specialist attention. The tutorial includes presentations of two models of the future organisational framework in which tele-medicine is applied. One of these is offered as a scenario in which delegates can role play the users and undertake an evaluation of the impact on the different stakeholders and consider how this might affect the generation of requirements from an organisational perspective.

This experience provides tutorial participants with an opportunity to assess critical issues associated with these techniques, for example, the kind of requirements it leads to, the forms of model and representation needed and the processes needed for effective user engagement.

\section{THE PRESENTERS}

Ken Eason and Susan Harker are human factors specialists who have worked on the human and organisational aspects of developing and implementing IT systems in user organisations for over 20 years. They are currently working on methods of requirements capture and have created the ORDIT methodology as a comprehensive process for establishing the Organisational Requirements of future Information Technology Systems.

\section{THE FORMAT OF THE TUTORIAL}

The first half of the tutorial is devoted to a description of a number of requirements capture methods and an evaluation of their strengths and weaknesses. The second half of the tutorial will introduce the ORDIT methodology, and through the use of a case study, participants will undertake a scenario evaluation in a role play exercise.

\section{REFERENCES}

1. Checkland, P. (1981) 'Systems Thinking, Systems Practice', Wiley, Chichester.

2. Eason K.D. and Olphert, C.W. (1996) 'Early Evaluation of the Organisational Implications of CSCW Systems'. In: Thomas, P. (ed) 'CSCW Requirements and Evaluation', Springer-Verlag, London, pp 75-89.

3. Emery F. and Trist E. (1969) 'Socio-Technical Systems' In Emery (ed) 'Systems Thinking' Penguin, London.

4. Kearney J. (1994) 'The Cost of Implementing Information Technology' Scientific American, September.

5. L.A.S. (1993)' Report of the Enquiry into the London Ambulance Service' London Ambulance Service.

6. Martin, M. J. and Dobson, J. E. (1991) 'Enterprise modelling and security policies'. In Jajodia, S. and Landwehr, C. E. (eds), Database Security: Status and Prospects IV, North-Holland, Amsterdam. 117-150.

7. Mumford, E. (1983), 'Designing Human Systems'. Manchester Business School Publications, Manchester. 8. Weisbord, M.R. (1990) 'Productive Workplaces; Organising and Managing for Dignity. Meaning and Community'. Jossey-Bass, Oxford. 